\title{
Manmade Rocky Shore Habitats Create Stress on Existing Biota
}

\author{
K. H. M. Ashoka Deepananda ${ }^{\#}$ and H. M. V. Udayantha
}

Dept. of Fisheries and Aquaculture

Faculty of Fisheries and Marine Sciences \& Technology

University of Ruhuna, Matara, Sri Lanka

${ }^{\#}$ Corresponding Author:

Tele: (94) 41 2227026; Fax: (94) 41 2227026; E-mail: ashoka@fish.ruh.ac.lk

\begin{abstract}
The present study investigated the effects of artificial rocky shore habitats on the wellbeing of intertidal macro-benthic communities. Manmade rocky shore which is constructed for preventing coastal erosion and natural rocky shore were selected as study sites from the Rumassala Marine Sanctuary, Galle, Sri Lanka. Stratified sampling method was applied to quantify the sampling biota from three zones along the tidal gradients at two study sites. Species richness index, species diversity and community evenness were calculated using PRIMER software. Index of disturbance, as a measure of stress was quantified for two communities. A total of 28 species were recorded from natural rocky shore environment compared to 13 species in the manmade rocky shore. Of the two communities studied, total number of individuals, species richness and Shannon Weiner diversity index was comparatively higher in natural rocky shore habitats. Index of disturbances were higher in natural rocky shore community, showing less stress to existing biota over the community existing in artificial rocky shore habitats. Present study indicates that man made habitat appears to be unable to support or attract the diversity and abundance of species found in natural rocky shore communities, and existing biota are in stressed condition..
\end{abstract}

KEYWORDS: Diversity, Index of disturbances, Macro-algae, Macro-invertebrates, Rocky shore

\section{Introduction}

Rocky shores, the most extensive littoral habitats on eroding wave exposed coasts throughout the coastlines of the world's oceans, are biologically rich and ecologically very important environment that include different habitat types like steep rocky cliffs, platforms, rock pools and boulder fields. This natural habitat is 
further increased by the plethora of artificial hard structures such as breakwater, jetties, docks, groynes, dykes and sea walls which are essentially functioning as artificial rocky shores (Crowe et al., 2000).

The organisms that live in rocky shore environment must be able to tolerate extreme changes in water level, wave action, temperature, moisture and salinity and, therefore shore plants and animals have evolved a variety of morphological, physiological and behavioral mechanisms to withstand the rigors of the shore, particularly for the aerial exposure and wave action (Raffaelli and Hawkings, 1999). Disturbance of the community by physical and biological factors may reduce the number of organisms in the community to the point at which there is less competition for resources, and hence less competitive exclusion and greater species diversity (Dethier, 1984). Therefore, rocky shores bear a large number of species of flora and fauna and they are especially rich in invertebrate fauna belonging to almost all invertebrate phyla.

South-west coast of Sri Lanka was subjected to very severe erosion, during the period of 1983-1984, and coastal erosion still continues to be a severe problem faced by Sri Lanka, leading to the damage or loss of infrastructure. It was recognized that any major coast protection work should form an integral part of an overall coastal erosion management plan and/or a coastal protection (Hettiarachchi and Samarawickrama, 2005).

There are several fragments of rocky shores that can be considered as artificial rocky shores constructed to prevent coastal erosion, off the coast of the Sri Lanka, especially in the western margin of the country. However, these rocky shores remain virtually untouched so far by experimental studies (Deepananda and Macusi, 2012). It was postulated that artificial rocky shores do not provide the better welfare for the existing biota compared to its conspecifics existing in natural rocky shores. The present study aimed to investigate the suitability of artificial rocky shores on the wellbeing of the intertidal life forms.

\section{Methodology}

Artificial rocky shore constructed by using boulders for protection of coast from erosion and natural rocky shore consisting similar structures were selected as study sites from the Rumassala Marine Sanctuary $\left(6^{\circ} 2^{\prime} 45 \mathrm{~N}\right.$ and $80^{\circ} 13^{\prime} 45 \mathrm{E}$ to $6^{\circ} 00 \mathrm{~N}$ and $\left.80^{\circ} 15^{\prime} 45 \mathrm{E}\right)$, Galle, Sri Lanka. These two sites consist of continuous rocky shore with rocky boulders. From each study sites, four sub-sites were selected randomly. At each sub-site, rocky beaches are arbitrarily divided into three zones along the tidal gradient. The divisions were high-tidal zone, mid-tidal zone and lowtidal zone. These three zones range from the upper limit of splash of spray zone in high-tidal zone to $0.5 \mathrm{~m}$ water depth at lower low-tidal zone, owing to steep profile of the shore. 
Study focused on benthic macro-invertebrate $(>5 \mathrm{~mm})$ and macro algae communities existing on studied intertidal rocky shore. Once a month, stratified sampling method was applied to collect the data over period of five months in 2008. A quadrate $\left(0.5 \times 0.5 \mathrm{~m}=0.25 \mathrm{~m}^{2}\right)$ subdivided into 25 equal squares was used for sampling biota. Tapes were used for positioning all quadrates. In short, transect tapes $18 \mathrm{~m}$ in length were placed parallel to the water fringe.

At each 3m intervals, quadrate was placed on landward side and seaward side one after one to the transect tape and abundance of macro-algae and colonial animals within each quadrate was quantified as percentage cover in the field while that of solitary animals was quantified as number of individuals. All benthic macro-algae and macro-invertebrates were scraped off with the aid of a metal scraper. Encrusted animals were detached from the substratum with the help of a chisel and hammer. Small boulders and stones in the quadrates were also turned for the collection of animals. The samples were placed in separate polythene bags and then samples were frozen in an ice filled container and transported to the laboratory.

All fauna and flora were identified to the lowest possible taxonomic level with the help of following literature and taxonomic keys; Atapattu, (1972); De Silva, (2006); Fernando, (2006); Jones and Morgan, (1994); Kirtisinghe, (1978); Fernando, (2005); Mallikarachchi, (2004). In addition, identification of macro-algae was confirmed by comparing the morphological characters and images found in worldwide algal database (www.algaebase.org). Samples were washed with tap water and Dry weight (DW) and Ash free dry weight (AFDW) of the samples were measured after incineration of Oven at $40-45{ }^{\circ} \mathrm{C}$ for macro-algae or at $110{ }^{\circ} \mathrm{C}$ for macro-invertebrates until attain constant weight and Muffle furnace at $450^{\circ} \mathrm{C}$ for 10 hours, respectively.

Ash free dry weight was calculated by following Deepananda and Macusi (2012). All percentage cover data were converted into individual numbers following Deepananda, (2008). Index of disturbance as a measure of stress (Pearson et al., 1982) was quantified for two communities, as well as for fauna and flora separately. Species richness indices (Margalef, 1958), diversity index based on proportional abundance of species (Shannon and Weiner independently derived function) and community evenness (Clark and Werwick, 1994; Pilou, 1996) were calculated using PRIMER (Plymouth Routines of Multivariate Ecological Research) software.

\section{Results}

A total of 28 species were recorded in the natural rocky shore environment compared to 14 species in artificial rocky shore. Of the 28 species in natural rocky shore, 19 species was macro-invertebrates and 9 species was macro-algae. In artificial rocky shore, 8 species was macro-invertebrates and 5 species was macro- 
algae. But, more than $50 \%$ of abundance at each study site was represented by four dominant species (Table 1). Abundance and biomass of species in two study sites at Rumassala Marine Sanctuary (RMS) as AFDW are summarized in Annex 1.

Table 1: Dominant species contributed to more than $50 \%$ of the abundance in artificial and natural rocky shores at RMS

\begin{tabular}{|l|c|l|c|}
\hline \multicolumn{2}{|c|}{ Natural Rocky Shore } & \multicolumn{2}{c|}{ Artificial Rocky Shore } \\
\hline Species & $\begin{array}{c}\text { Species } \\
\text { Abundance }\end{array}$ & \multicolumn{1}{c|}{} \\
\hline Cellana radiata & 21 & $\begin{array}{l}\text { Chaetomorpha } \\
\text { antennina }\end{array}$ & 32 \\
\hline $\begin{array}{l}\text { Centroceras } \\
\text { clavulatum }\end{array}$ & 15 & Clypidina notata & 23 \\
\hline Littoraria scraba & 14 & Cellana radiata & 12 \\
\hline Asporagopsis sp. & 06 & Centroceras clavulatum & 07 \\
\hline
\end{tabular}

Total number of individuals, species richness index (Margelef) and Shannon Weiner index was higher in natural rocky shore habitats in comparison with artificial rocky shore habitats. In contrary, Pielou's evenness was higher in artificial rocky shore compared with the natural rocky shore (Table 2).

Table 2: Total number of individuals, species richness, community evenness and Shannon wiener diversity index in natural and artificial rocky shores of RMS

\begin{tabular}{|l|c|c|}
\hline \multicolumn{1}{|c|}{ Item } & $\begin{array}{c}\text { Natural Rocky Shore/ } \\
\mathbf{9 0 \mathbf { m } ^ { \mathbf { 2 } }}\end{array}$ & $\begin{array}{c}\text { Artificial Rocky Shore/ } \\
\mathbf{9 0 m}^{\mathbf{2}}\end{array}$ \\
\hline Total individual number & 1826 & 786 \\
\hline $\begin{array}{l}\text { Species richness index } \\
\text { (Margelef) }\end{array}$ & 3.60 & 1.95 \\
\hline Pielou's evenness index & 0.75 & 0.81 \\
\hline Shannon Weiner index & 2.49 & 2.12 \\
\hline
\end{tabular}

Index of disturbance which is the biomass to abundance ratio were higher in natural rocky shore habitat (value 0.10 ), showing less stress to the existing community, whilst that of in artificial rocky shore habitat was lower (value 0.07), showing high stress to the existing biota. Likewise, index of disturbance for fauna and flora separately showed the similar trend, indicating higher stress in biota existing in artificial rocky shore (Figure 1). 


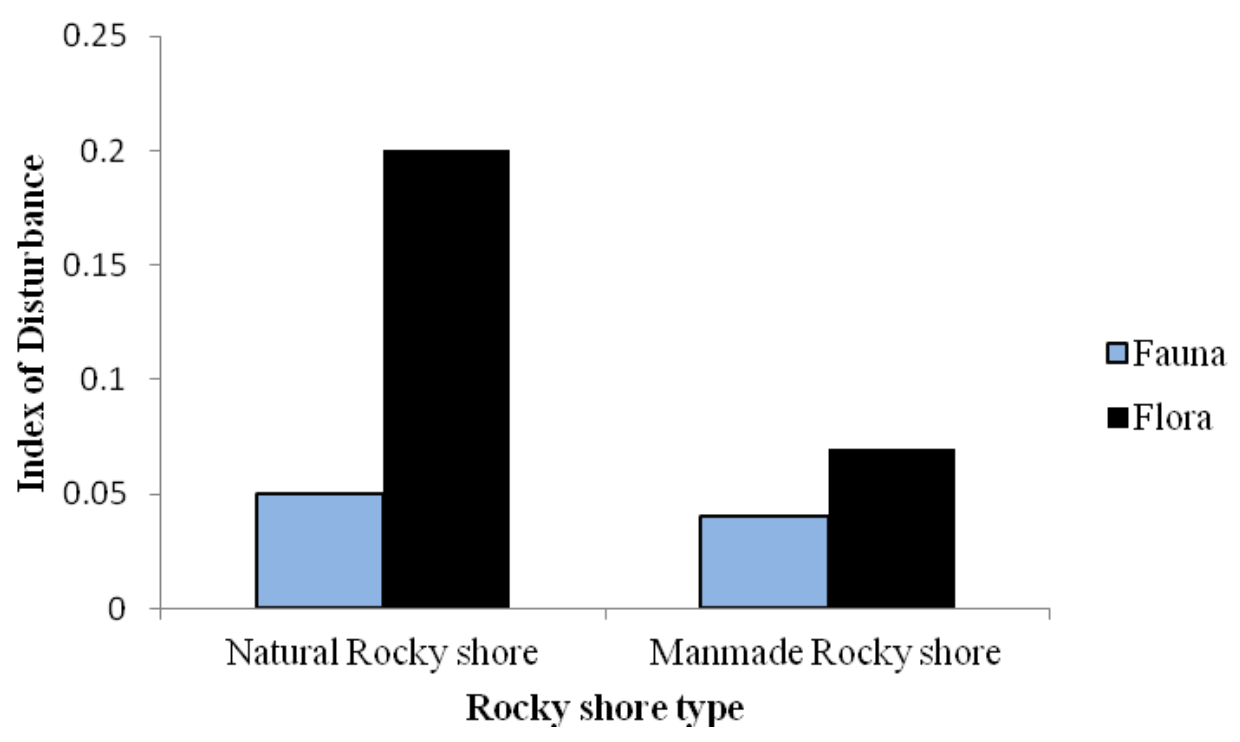

Figure 1: Index of disturbance for flora and fauna existing in natural and artificial rocky shore habitats in RMS

\section{Discussion}

Of the two communities studied, the total number of individuals, species richness and Shannon wiener diversity index was comparatively higher in natural rocky shore habitats. In contrary, community evenness was higher in artificial rocky shore. Index of disturbances were higher in natural rocky shore community, showing less stress to existing biota over the community existing in artificial rocky shore habitats.

Present work investigated the impacts of natural and artificial rocky shore habitats on the wellbeing of the existing biota. Study has quantified the stress created by natural and artificial rocky shore habitats on existing benthic macro fauna and flora. Stress is the response of biological entity (individual, population, community etc.) to a disturbance or stressor. Stress at one level of organization (e.g. individual, population) may also have an impact on other level, for example, causing alterations in community structure (Crowe et al., 2000).

Communities and community changes over time due to such disturbances or stressors can be analyzed and characterized in different ways. One of the most common methods is by looking at community diversity which is a measure of complexity of the community (Laetz, 1998). In the present work we assessed the community diversity together with the Index of disturbance to compare the stress on the community, as this index is well represents the real condition of the existing 
biota. Benthic macro-organisms are used in the present work, as they are the best representative to ascertain any impact to intertidal community, due to their limited mobility.

Species richness and heterogeneity diversity measures have most commonly been used to access the impact of disturbances on marine environments (Laetz, 1998: Grey, 2000). The number of species and individual number of organisms are higher in natural rocky shore environment. It emphasized that artificial rocky shore habitats do not attract the species and thereby having less community interactions. Dominant species of the two communities have given the clear picture on this argument.

More than $70 \%$ of species abundance was represented by four dominant species in artificial rocky shore. That is, Chaetomorpha antennina, Centroceras clavulatum were the most dominant floral species, and Clypidina notata and Cellana radiata were the most dominant species of fauna. But, in natural rocky shore habitat, only $50 \%$ of the species abundance is covered by the most dominant four species. That is, floral species of Asporagopsis sp., Centroceras clavulatu, and fauna species of Cellana radiata and Littoraria scabra were the most dominant species in natural rocky shore.

This clearly implies that natural rocky shore habitats organisms have higher community interactions and it does not allow one or two species to be prominent in the community. This has also proven by the computed diversity index, i.e., Shannon Weiner index were higher in natural rocky shore compared to that of in manmade rocky shore habitats. It shows the fewer disturbances by natural rocky shore habitats for the existing biota. This higher diversity is mainly due to the availability of microhabitats to the existing organisms in natural habitats. It can be argued that naturally occurring microhabitats like crevices and caves etc. attract more species to the community. Those microhabitats are more important for the biota to protect from the extreme wave action and also from the desiccation. This may increase the species interactions more efficiently, and does not allow one or two species to be dominant in the community.

This argument can be well explained by the community evenness. In natural rocky shore habitat, especially the fauna prefer to cluster in available microhabitats in order to avoid extreme conditions, resulting low evenness. In contrary, unavailability of naturally occurring microhabitats leads the higher evenness in the community thriving in manmade rocky shore habitats.

This argument based on the species abundance and diversity is well explained by the computed index of disturbances for two communities. The biomass and abundance of the organisms are well explained by the index of disturbance and it is very useful to understand disturb and non-disturb communities in various habitats. 
Here, biomass to abundance ratio (B: A) shows the stress imposed by natural and artificial habitats to communities and high value of index of disturbance shows the less disturbance because of fauna and flora grows well in non stressed conditions (higher biomass). In artificial habitats, growth rate and growth of the biota are low due to the stress conditions. Therefore, community as whole shows low B: A ratio compared with natural rocky shore. Moreover, Index of disturbance for the fauna and flora separately also shows the high stress on biota in manmade rocky shore over natural rocky shore.

\section{Conclusions and Policy Implications}

Present study reveals that both flora and fauna in artificial rocky shore habitats are in stress condition over those existing in natural rocky shore habitats. This may be due to unavailability of suitable microhabitats for thriving them. This means that coastal resource managers and the public should not expect that manmade structures such as breakwater structures, while they are a necessary part of coastal development, can replace the need for and conservation of natural rocky shore habitats.

\section{Acknowledgement}

Authors would like to acknowledge Mr. I.D.K.L. Fernando and Mr. N.M.B.G. Nishshanka for their support in field data collection.

\section{References}

Atapattu, D. H. (1972). "The Distribution of Mollusks on Littoral Rock in Ceylon, with Notes on their Ecology" Marine Biology, 36: 63-71.

Clarke, K. R. and Warwick (1994). "Change in marine communities: an approach to statistical analysis and interpretation". National Environment Research Council, United Kingdom, 1-144pp.

Crowe, T. P., Thompson, R. C., Bray, S. and S.J. Hawkins (2000). "Impact of anthropogenic stress on rocky intertidal communities" Journal of Aquatic ecosystem Stress and Recovery, 7: 273-297.

Deepananda, K. H. M. A (2008). "Community-level analysis of anthropogenic impacts on rocky shore communities in Sri Lanka" Available from Nature Proceedings. http://dx.doi.org/10.1038/npre.2008.2317.1

Deepananda, K. H. M. A. and E. D. Macusi (2012). "Human disturbance on tropical rockyshore assemblages and the role of marine protected areas in reducing its impacts" The Phillipine Agricultural Scientists, 95: 87-98. 
De Silva, D. (2006). "Current status of taxonomy and ecology of marine mollusks in Sri Lanka" The fauna of Sri Lanka, 274-287.

Dether, M. N. (1984). "Disturbance and recovery in intertidal pools: maintenance of mosaic patterns" Ecological Monograph, 54: 99-118.

Fernando, M. (2005). "Nudibranchs: Snails without homes” Loris, 22(3): 4-12.

Fernando, M. (2006). "Coral associated invertebrates: An overview of the current taxonomicstatus. The Fauna of Sri Lanka, IUCN-World Conservation Union, 259273.

Gray, J. S. (2000). "The measurement of marine species diversity, with an application to the benthic fauna of Norwegian continent shelf" Journal of Experimental Marine Biology and Ecology, 250(1-2): 23-49.

Hettiarachchi, S. S. L. and S. P Samarawickrama (2005). "Planning and implementing coastal management in Sri Lanka" Proceeding of the Institute of Engineers, Maritime Engineer, 158: 25-32.

Jones, D. S. and G. J. Morgan (1994). “A field guide to crustacean of Australian waters". Reed publishers, Australia. pp. 1-209.

Kirtisinghe, P. (1978). "Sea shells of Sri Lanka". Charles E. Turtle company, Inc. of Rutland, Vermont \& Tokyo, Japan, pp 1-202.

Laetz, C. (1998). "Marine benthic invertebrate communities near king country's waste water out falls" Puget Sound Research, 754-759.

Mallikarachchi, M. A. U. (2004). "A study of the taxonomy and distribution pattern of algae on the southern coast of Sri Lanka with special reference to anthropogenic effects". Thesis submitter for the degree of Master of Philosophy of the University of Ruhuna, Sri Lanka.

Margalef, D. R. (1958). "Information theory in ecology" International Journal of General Systems, 3:36-71.

Pearson, T. H., Duncan, G. and J. Nuttall (1982). "The Loch Eil project: Population flucyuation in the macro-benthos" Journal of Experimental Marine Biology and Ecology, 56: 305-321.

Pilou, E. C. (1966). "Species-diversity and pattern diversity in the study of ecological succession" Journal of Theoretical Biology, 10: 370-368.

Raffaelli, D. and S. Hawkins (1999). "Intertidal Ecology". Kluwer Academic Publisher, London, pp 1-356. 
Annex 1: Species abundance and biomass as AFDW in two study sites of RMS. Zero values donates that relevant species was not recorded at the study site

\begin{tabular}{|c|c|c|c|c|}
\hline \multirow[t]{2}{*}{ Species } & \multicolumn{2}{|c|}{ Natural rocky shore $/ 90 \mathrm{~m}^{2}$} & \multicolumn{2}{|c|}{ Artificial rocky shore/ $90 \mathrm{~m}^{2}$} \\
\hline & Abundance & AFDW & Abundance & AFDW \\
\hline Asporagopsis sp. & 107 & 44.61 & 0 & 0 \\
\hline Cellana radiata & 387 & 10.53 & 82 & 2.87 \\
\hline Centroceras clavulatum & 282 & 20.31 & 51 & 2.61 \\
\hline Chaetomorpha antennina & 72 & 26.36 & 230 & 147.54 \\
\hline Chnoospora minima & 42 & 5.69 & 49 & 2.28 \\
\hline Clypidina notata & 104 & 5.09 & 160 & 4.5 \\
\hline Drupa (Morula) granulata & 3 & 0.14 & 0 & 0 \\
\hline $\begin{array}{ll}\text { Drupa } & \text { (Morula) } \\
\text { margariticola } & \\
\end{array}$ & 1 & 0.02 & 0 & 0 \\
\hline Grateloupia lithophila & 21 & 3.59 & 0 & 0 \\
\hline Ahnjeltiopsis pygmaea & 11 & 0.16 & 0 & 0 \\
\hline Laurensia obtusa & 34 & 2.66 & 0 & 0 \\
\hline Ligia sp. & 14 & 0.24 & 0 & 0 \\
\hline Littoraria scabra & 248 & 4.66 & 54 & 1.03 \\
\hline Littoraria undulate & 17 & 0.71 & 0 & 0 \\
\hline Littorina sp. & 5 & 0.01 & 0 & 0 \\
\hline Melampus flavus & 50 & 0.65 & 0 & 0 \\
\hline Mytilus crassitestatus & 15 & 0.12 & 65 & 0.61 \\
\hline Nerita $($ Retena $)$ costata & 28 & 6.82 & 4 & 2.02 \\
\hline Nerita albicilla & 4 & 0.35 & 0 & 0 \\
\hline Nodilitorina granularis & 231 & 1.58 & 18 & 0.09 \\
\hline Nodilitorina pyramidalis & 34 & 0.24 & 0 & 0 \\
\hline Notohaliotis sieboldi & 1 & 1.07 & 0 & 0 \\
\hline Saccostrea cucullata & 1 & 0.82 & 4 & 0.59 \\
\hline Sarcodia montagneana & 87 & 16.61 & 0 & 0 \\
\hline Thais rudolphi & 5 & 8.44 & 0 & 0 \\
\hline Trochus radiatus & 8 & 0.46 & 0 & 0 \\
\hline Ulva rigida & 10 & 3.47 & 0 & 0 \\
\hline Valonia fastigiata & 4 & 15.44 & 0 & 0 \\
\hline Acanthopleura sp. & 0 & 0 & 19 & 10.85 \\
\hline Enteromorpha intestinalis & 0 & 0 & 24 & 0.76 \\
\hline Gelidium pusillum & 0 & 0 & 22 & 3.09 \\
\hline
\end{tabular}

